\title{
Prospects of the Interdisciplinary \& Systemic Approaches
}

\author{
Oleg N. Yanitsky \\ Federal Center of Theoretical and Applied Sociology of the Russian Academy of Sciences, Moscow, Russia \\ Email: oleg.yanitsky@yandex.ru
}

How to cite this paper: Yanitsky, O. N. (2020). Prospects of the Interdisciplinary \& Systemic Approaches. Creative Education, 11, 913-925.

https://doi.org/10.4236/ce.2020.116066

Received: May 31, 2020

Accepted: June 26, 2020

Published: June 29, 2020

Copyright (c) 2020 by author(s) and Scientific Research Publishing Inc. This work is licensed under the Creative Commons Attribution International License (CC BY 4.0).

http://creativecommons.org/licenses/by/4.0/

\begin{abstract}
Drawing on the long-term studies of the relationships between the natural, social and technical sciences, on my participation in the three international projects and the own empirical investigations of natural and technological disasters, I came to the following conclusions. First, a mono-disciplinary approach to modern multisided transformations has become outdated. Second, all modern events including critical situations have systemic character. Third, any systemic events or processes should be studied by the interdisciplinary approach. Four, the modern world has nonlinear, uncertain and unpredictable character. Five, any environment has double i.e. passive-active nature, therefore when its carrying capacity is overcoming it usually transforming into a multisided actor. Six, recently the situation has aggravated by the still ill-studied process of transformation of the Biosphere into the sociobiotechnosphere (hereafter the SBT-system). Seven, its feedback in relation of humanity is ill-studied as well. Eight, this SBT-system may have various degrees of integrity, from the chaotic, over complex and hybrid till a full systemic character. Nine, various metabolic processes are the main "integrator" of natural and social sciences. Ten, any environment has its own carrying capacity. In sum, if one takes into account the above considerations, the systemic and interdisciplinary approaches are the best way to making the models of future SBT-systems. But at the same time, in our tightly integrated world, the systemic and interdisciplinary approaches have their limits because these approaches are only the scientific but not the political instruments.
\end{abstract}

\section{Keywords}

Actor, Biosphere, Globalization, Ecology, Hybridization, Interdisciplinary Approach, SBT-System, Science, Systemic Approach, Russia 


\section{Introduction}

\section{1) Why these approaches are necessary?}

From the times of the Enlightenment i.e. from the XVII century and forward the science as a social institution has been developed mainly monodisciplinary. For the European culture it has been a mean for the establishment of its dominating role across the world. But by and large, it has become clear that all parts of economic production and social reproduction, it is insufficient because the very social activity of humanity has never been one-sided only. The further the more this activity has become more and more complex.

The complexity phenomenon has gradually embraced all spheres of human activity, a household, resources extracting and industrial production, market, exchange networks (logistics), consumption system and so on and so forth. With the further development of productive forces and the mastering of new parts of the global whole the complexity of human activity has been forced to become complex as well. Very slow but persistently such complexity has been growing generating new fields of the sciences.

In the XX century, especially after the WWI the scientists moved forward two basic ideas or principles of humanity-nature relationships. The outstanding Russian biochemist and political thinker Vl. Vernadsky (1977) offered two basic concepts namely the Biosphere as a very complex wholeness and that the science is a planetary phenomenon. It's clear that these two concepts are tightly interdepended in the time and space. The time issue will be analyzed further (see part 8) but here it's necessary to fix their interdependence.

But to fix the above interdependence and to study of their structural-functional organization and interrelated dynamics are two quite different things. Vernadsky had underscored that a researcher has always to be in the midst of a natural and social life.

It signifies that humanity has entered in a qualitatively new period of its existence. To be "in the midst" means that the all parts of the Biosphere irrespectively to their origin and nature are closely interdependent, as concerns to the science as a social institution, it means the end of monodisciplinary studies as the mainstream of its development and turns to an interdisciplinary approach. From this viewpoint, such methodology approaches, as the cross-disciplinary or trans-disciplinary ones seem to me groundless.

The difference between the systemic approach and interdisciplinary one is obvious. The former is fixed the relationships and mutual transformations of the structural-functional elements of the Biosphere while the latter is resembled them in the scientific language. But it's only the first steps on the long way of the making these methodological approaches ready to practical use in social practice of multitude of the agents of our contradictory and permanently competing global whole.

Besides, to my mind, we are living now not in the Biosphere but in the global SBT-system created by the joint activity of humanity. This SBT-system exerts a 
permanent feedback on the natural and social ecosystems. This feedback the some branches of natural science only begin to investigate, while the social and humanitarian sciences not yet. In sum the further the more, all branches of sciences are lag behind in the studies of relationships between the dynamics of the global SBT-system and its integrated comprehension.

It's a great global risk because nowadays the scientific researches shouldn't follow the already happened events including the disasters and other critical situations (hereafter, the CS) but to outstrip them (Yanitsky, 2014). This is a great challenge to all sciences because, as the already happened pandemics clearly showed, a microscopic virus may cause the global critical situation with enormous and endless human and material losses.

\section{2) The basic ecological principles}

From my viewpoint, the monodisciplinary approach which has been socially institutionalized and developed from the XVII century up to now has prevented the development of an ecological approach created by the Fathers of the Chicago school of human ecology nearly 100 years ago (Park et al., 1926; Park, 1928, 1952). It's very curious that Russian scientist acad. Vernadsky and his followers created the Biosphere concept nearly in the same years. But R. Park and his colleagues had created his human ecology concept on the basis of mass migration of the Europeans to the USA after the WWI while acad. Vernadsky had initially been the global thinker and theorist. But they all had been ecologically-oriented researchers.

The underpinning principles of global ecology formulated by the US biologists B. Commoner areas following: the all tightened with all, the all is going somewhere, and the nothing is given gratis, i.e. free of charge (Commoner, 1971).

R. Park, B. Commoner, V. Vernadsky had been true geniuses. But simultaneously they have been materialists relying upon the wisdom of humanity who didn't allow any distractive actions in relation of natural and social communities and to the Biosphere as a whole. Even acad. Vernadsky who had been in the 1930s the head of Soviet uranium project had considered the uranium as a potential source of a cheap energy for humanity but not for the nuclear war!

What the current pandemics already clearly showed to us and to humanity of a global scale. First, that we badly know our world, be it natural, social or artificially-constructed. Under the last I understand modern information-communication technologies. Recently, our world involved into the arms race and technological race. Second, for this reason we have forget two important things, the one is that the Biosphere has its own laws of functioning and development, and the other the abovementioned transformation the Biosphere into the global SBT-system with its own feedbacks.

Second, a long-term investigations in the limits of grows sponsored by the Club of Rome during fifty years gave neither substantial theoretical nor practical results (Meadows \& Meadows, eds. 1973; Meadows at al., 1989; Von Weizsäcker \& Wijkman, 2018). On the contrary, as the long-term research project on global 
risks carried out by the World Economic Society clear-cut showed (Global Risk Report, 2018) the threat of global conflicts and disasters has been permanently grown. Therefore, it's quite natural that the fundamental work on social ecology in the digital era (Stokols, 2018) doesn't even approaching to the new qualities of global environment.

In any case the metabolic processes are the main integrators of a majority of interactions within various ecosystems and between them.

3) The theoretical underpinnings: nonlinear, uncertain and unpredictable

It's one of the key issues because up to now the majority of modern sociological concepts have been relied upon the following methodological principles. First, they all have been based on the principle the already happened event (a change, disaster, critical situation etc.) and then an analysis of its after-effects (Beck, 1999). It has been a norm of work of the theorists and researchers because they have neither motivation, nor experience in the prognostics thinking and designing.

Second, they did so because they didn't take into account that a time parameter of the objects with which they operated is a very important parameter of their research, decision-making or designing.

Third, the majority of the theorists and researchers have practiced the monodisciplinary that is one-sided approach. But in our interdepended and mobile world there is no phenomenon with the one-sided characteristics which may be described, for example, in the terms of its length or width only.

Four, it means that even the one-sided projects of development, for example a medicine institution, should be the system and therefore an interdisciplinary models. More than that, in our tightly interdependent world any kind of constructive thinking or activity should be systemic and therefore interdisciplinary.

Five, such complex thinking and doing should take into account its space-time parameters that, in turn, are dependent on transformations of other static or dynamics actors of a global whole.

Six, it means that any study of a certain complex object should combine its already existed dynamics with a modelling of its possible future development in the context of the dynamics of the global SBT-system. I've named this multisided methodological approach as the principle of a total complexity.

Nevertheless, all said above is the only necessary introduction (prelude) to some basic characteristics of a study of any natural, social or built objects of the theoretical interest.

As it has already been mentioned in the heading of this part, the nonlinearity, uncertainty and unpredictability are the main characteristics of a structural-functional transformation of an overwhelming majority of the agents of our planet.

The three already mentioned characteristics are defined by their connections with other active and static objects of the global SBT-system. Therefore, their uncertainty, for example, is usually defined by their multisided interdependence 
with the other structures and processes as well as with inert structures of this global system. It signifies that such uncertainty is one of means of its survival or further transformations.

Of course, an origin and size of a particular element of this permanent turnover do matter. For example, the statics character of the Gulfstream is incomparable with statics of a certain microorganism. Nevertheless, they both are dependent on their capacity of adaptability to the changing environmental conditions. Or, on the contrary, the destructive after-effects will have another trajectory and timing.

And here is another factor of their difference. As the current pandemics have clearly showed, a destructive after-effect of it has been repeatedly strengthened by such social factors as all-embracing global mobility of the people, information, trade, etc. (Urry, 2008). Earlier, the same author has underscored that a global complexity is capable to produce still unknown risks and global disorder (Urry, 2003). This point has indicated to us a new dialectics. On the one hand, the constructors tried simultaneously to make the things (gadgets, cars and many others) more and more compact and multifunctional. On the other hand, so doing the constructors make these very compact devices more fragile and dependent on the fluctuations of an environment.

In sum, the more our world is becoming the nonlinear, uncertain and unpredictable the more difficult to predict its future that will be full of the twists and turns. In order to diminish these risky qualities of global dynamics a modern global agenda should be reconsidered. I'm not a politician but I'm convinced that such social institutions as the science, education, medicine and social security should come to the forefront. As a sociologist I'm convinced that if we have the above institutions well-developed a global losses, human and economic, would be much less.

\section{4) From the Biosphere to the global Sociobiotechnical system}

I see necessary to introduce the above concept for the following reasons (Yanitsky, 2016).

First, I've relied upon the works of the naturalist and systemic analysts, especially those who has studied the transformations of a man-nature relationship in the run of human history (Fisher-Kowalski, 1997).

Second, Vl. Vernadsky (1977) in his concept of the Biosphere clearly indicated that the notion of a 'living substance' has included humanity and its activity whose role in the transformation of the Biosphere into the global SBT-system is permanently grown.

Third, the abovementioned and other investigations showed that various metabolic processes inside the natural and social ecosystems and between them played the key role in their interdependence and integration. It again follows that humanity is an integrated part of the Biosphere. Four, the UNESCOs program 'Man and the Biosphere' in which I had been an active participant has confirmed the above thesis (Deelstra \& Yanitsky, 1991). 
Five, two years ago two public committees of the UNESCO, namely of the Natural and Social sciences have merged in the united committee of sciences. It has been an impetus for joint efforts of the naturalists and sociologists to the study of the Biosphere as inseparable nature and man-made whole.

Six, from the 1972 onwards every four years the international conferences have been held on the man and the Biosphere relationships.

Seven, there were a set of the international climate meetings and conferences but without sufficient and practical results.

Eight, as to my own works, drawing on the fundamental works of acad. Vernadsky and many my Russian and foreign colleagues including the members of the International Socio-Ecological Union and works of the researchers of the Russian Federation, I began to develop the global SBT-concept. To my mind, the concept of the Anthropocene gives us nothing because such epoch has begun many thousands years ago whereas we are needed in the concept which could be applicable to the modern conditions.

Nine, I'm convinced that a key notion or, more correct the concept is various metabolic processes the studies of which will allow to the scientists from all branches of this institution to understand each other and to work together because the metabolic transformations will show to all of us which global and local changes are going on.

So, I'd to underscore once more that the notion of metabolism is applicable to the studies not only of natural structures and processes but for social processes and organisms of various scale and configuration.

\section{5) A critical turn: an environment as a teacher}

For a long time the interactions of earth inhabitants with its natural and social environment serve to the people as a teacher. But from the ancient times up to now the children, students and other inhabitants received the necessary knowledge after the selection and generalization of empirically-gained data. Besides, any new knowledge has been a product of its distillation by a special institution of an education and enlightenment. It means that the initial, i.e. empirical knowledge has been many times prepared and interpreted through particular ideological and political lenses.

In the XX century with the emergence of the information and communication networks the situation has radically changed. To have an official diploma of the education has been still necessary, but the further the more the employer has required from the employee a practical (and permanently changing) knowledges and crafts which have been needed to a particular mode of production.

Nobody has fixed the gap between the knowledge accumulated by the employee during 15 - 17 years of education and very flexible knowledge plus crafts that have been required here and now. The flexibility and retraining have become the key notions.

It means that both a very complex and movable work and living environment have become the teachers (or, more exactly, the tutors) of the majority of urban 
inhabitants. It doesn't mean that I reject the teaching. On the contrary, the process of teaching has become much more complex and uninterrupted. As I've already mentioned (Yanitsky, 2019), the triad, namely, the scientists, teachers and students, has turned into the constant pupils of their permanently changing living environment.

But the further the more the changing environment has outstrip the reflection of ongoing transformation in the sciences and practice. As a result, the social and environmental movements came to the forefront. It means that that some forms of education have become outdated. The struggle between education institutions which have produced numerous "rules of games" (norms, forms, requirements, protocols, etc.) and well educated and practically trained members of environmental and other civil initiatives and movements have begun.

Besides, the gap between the monodisciplinary profiles of institutionally-stable branches of education processes and tightly integrated and mobile living environment is growing. It has been quite natural because the above monodisciplinary profiles didn't take into account the processes of metabolic transformations. It is they are the key moments of the 'man-environment' relationships (see next Part).

But it's not all. Any environment is a kind of living organism, and it has its own limits of functioning as it is. But if its carrying capacity has been exceeded it turns into numerous agents, natural, social or geopolitical. We should to remember that the current environmental threats have many faces from sharp weather fluctuations and long-term climatic changes till a biological, nuclear and informational attacks. Therefore, to design any prospects of future development without the understanding in what environment it will be, it's a wrong way of making the plans and prognoses. It's obvious that the rich and the poor have quite different opportunities to create their local milieu relatively safe. In any case the safety came to the forefront. Some practical recommendations concerning the integration of natural, social and technical sciences have been laid down in (Yanitsky, 2019a).

\section{6) A systemic and social metabolism division}

Such division is very conditional, and I've made it pursuing the methodological purposes only. Generally speaking, the metabolism as an integrated part of natural and social ecosystems and their interactions and merging has a very complex structure because it essence and forms have developed with the evolution of the Biosphere ant its gradual transformation into the global SBT-system. In the primitive societies it has one forms, in the traditional, another ones, in the industrial, quite another, etc.

And recently, under conditions of the Fourth industrial revolution (Schwab, 2016) one can see the new picture. The metabolic processes have become the all-embracing forms of the global SBT-system existence and functioning. Nowadays, any ecosystem is inherently the metabolic one. And in each of the above a man-nature relationships the metabolic processes have been presented in var- 
ious forms. For the research aims I've divided their current existence in the following stages (of phases).

The first one is the metabolism by chance. Here I mean the metabolism within natural ecosystems only i.e. without the man's participation. Such metabolic processes and transformations are permanently going on in the above ecosystems in the processes of hunting as well as under the influence of an environment in which these ecosystems exists.

Conditionally speaking, I may call such metabolism as "natural one" that has existed without man's participation.

The second one I've called as a quasi-metabolism. Under it I mean an accidental metabolism which usually took place without the direct man's participation. Usually the quasi-metabolism has happened as a result of natural and man-made disasters but the people perceived it as an accident or the God's punishment for their previous sins.

The third one maybe considered as a cascade effects of already happened accidents or natural disasters and technological catastrophes. If such after-effects is well-seen is the one thing but if they are totally unseen and maybe revealed by a special scientific and technological instruments only it's quite another story. Let me mention that such unseen and long-term cascade after-effects is one of the acute issues of modern interdisciplinary research.

The fourth one is that which are usually named as hybrid systems. But actually it may be simply the constructions i.e. very complex artificial systems created and tested by the teams consisted of the mono-disciplinary professionals but who well understand each other. This degree of the hybridization is very close to an actual interdisciplinary research because the members of such collaborative teams began to master two or three other professions. And what is the most important these colleagues have gradually mastered to translate from one scientific language to the other one. The development of such translation is the turning point to an interdisciplinary research methodology and theory.

The fifth step is a partial integration of the hybridization and true metabolic transformations that is the combination of biodegradable but inert elements with the living organisms of a men or animals. Such combinatorics is already used in the medicine and in some other forms of human activity. The aircraft is the most simple example of such combinatorics which 'consists' of a very compel construction with its personnel and passengers.

It has been a great achievement of the interdisciplinary thought but every type of combinatorics has it limits. Say, the overestimation of the possibilities of programmed government of the passengers' aircrafts (so-called button government of them) led to a set of catastrophes with human losses.

The sixth and the most difficult case are the study and forecasting of the metabolic processes of the Biosphere transformation into the global SBT-system, and its feedbacks in relation to the Biosphere and humanity. The matter is that such feedbacks may have a quite different effect in comparison with the initial 
direct impact or strike. Humanity has to be prepared to the already happened and coming climatic fluctuations. Thus, the global ecosystem forecasting is coming to the forefront. Some details of already happened events of global scale and the relationships between the Biosphere processes and their current fluctuations and their environmental and social preconditions see in detail in: (Simonov, 2020).

Let me remind that a social metabolism has existed as well. I see such notion necessary because the notions like an interactions and communication says us in the best case about the existence of such ties between the users, the people or companies, but only indirectly we may judge about the character and social relationships between those who involved in these processes. If we turn to the study of social networks the result would be the same. Of course, the very fact that two or group of the persons gives to the researcher the certain information related to the theme of their contacts, their frequency, timing, amount of the likes, etc. Nevertheless, such studies give nearly nothing information concerning their one-sided or mutual social metabolism. But the understanding the concrete or postponed results of such interactions isn't possible to receive. And the conclusions of some outstanding European sociologists that the Internet-communication is gradually diminished the social inequalities between the reach and poor are very doubtful.

\section{7) The concept of critical situation}

The current pandemics showed that it is not usual crisis. The economic crises are coming and disappearing whereas now the global community is dealing with the true critical situation (hereafter the CS). Roughly speaking, the pandemics as the CS are the global catastrophe with inevitable human, economic, natural and other losses. Besides, the pandemics clearly showed to all of us that the all tightened with all, the all is going somewhere, and the nothing is given gratis, i.e. free of charge. It means that we are living in a global tightly integrated sociobiotechnical system in which its structures and processes are tightly intervened and integrated. The current COVID-19 pandemics and its all-embracing consequences have actually confirmed that this global CS is the systemic one and it requires the interdisciplinary research.

But it is not all. All professional and ordinary people have already seen that there is no certainty in this CS development. It signifies that this CS is inherently uncertain if not entirely chaotic. It's a great scientific problem to outline the possible laws or trajectories of its evolution as a certain whole. This issue is becoming even more serious, if we attempt to take into account all possible transformations generated by numerous unseen metabolic transformations and their cascade effects. Does it mean that the trajectories of global evolution are becoming chaotic and unpredictable? I'm not so pessimistic but just now I have no ideas on how to resolve this task of the highest complexity and uncertainty. I name this task as the position between the Scylla and Charybdis, i.e. between the wish to restore the already existed social order and the understanding that after this CS our world will be qualitatively another. It means that our world is in the 
next transition period (Yanitsky, 2019), or as it has been named by Bauman (2017) as an interregnum.

Why it is so serious? The matter is that we, the researchers are between two fires. On the one hand, as I've mentioned earlier, the use the principle of the after-effects studies give us nearly nothing because there are no chances that the CS under consideration will be developed linearly. It's already clear that in the best case such CS as the pandemics will be developing in a waving manner with unknown space width and length in time. On the other hand, the amount of material, resource and human losses as well as their cost is also very difficult to predict.

\section{8) The issue of global timing}

This issue is very complicated and therefore deserved special attention. Thus, I'd like only to mention that there is a fundamental contradiction between a will to fasten human development and the principle of the sustainable development of the global whole and of all its human communities. To my mind, it's a kind of the theoretical deadlock because recently any sustainability is only the moment in the developmental processes. In the 1980s, when the world had experienced the permanent transformations the idea of the sustainable development of the whole world (Brundtland \& Khalid, 1987) had been well understandable. But nowadays, especially in the state of global turmoil generated by the pandemics coupled with a severe economic crisis this idea seems to me as a kind of wishful thinking.

Until the global pandemics under consideration the business, politics and other institutions of the global community have been guided by the slogan the "Time is Money". Therefore it's a bit surprising, that up to now the issue of the speed of a development has been discussed and investigated by a scientific community so rare. Under conditions of global market economy with its permanent tough competition the time of development (transformation or decay) of its each participant is one of the key resources. In the run of permanent processes of redistribution of leading forces on the global arena (I mean the processes of shaping of the states' alliances and their reconfiguration) the time speed has simultaneously becoming an important resource and mighty weapon. But up to now, the researchers of global transformations have been dealt with more or less predictable changes in the social and political significance of local-global timing.

There are at least two more unstudied things. The first one is a feedback of any global critical situations. Or, more generally, the question is about the feedback of the global SBT-system in relation to the nature of our planet and its inhabitants. The second one is the question about the tempo-rhythms of the cascade effects of already happened CS.

The relationships between the development the timing of the pandemics and economic crisis is the most difficult question. Are they closely interdependent, independent or stimulating each other? When, in what succession they have 
emerged, all simultaneously, or gradually one by one are the main questions here. Anyhow, the current CS is the systemic critical situation which requires interdisciplinary approach.

The reverse side of the same coin is a process of rehabilitation of various businesses. What are the first: the human needs or the rehabilitation of business and its infrastructure? In what proportion and succession such rehabilitation should be done? And the following fact is very surprising. It's appeared that in the CSs the course of the time is speeding up! But simultaneously the question arises: in what direction, back of forward? The some people want to restore an already existed order as soon as possible while the others are striving to establish a new, more just social order.

The poor, jobless and affected by the particular CS are needed in an immediate help, and first of all in the drinking water, meal, medicine and shelter. For these categories of world population (billion people) the score is in the minutes. These categories need help 'here and now' because they are usually immobile. The UN sees the current global situation as catastrophic one. But as everybody can see, initially the majority of national and international political leaders including the UN one didn't pay necessary attention to the emergence of the global pandemics. It has been quite natural because they haven't been prepared to such unintended and already well-forgotten global threat (I mean the epidemics of Spanish flu). As concerns to Russia, many of its citizens, the reach and the poor, want to participate in various charity actions. It means that a total amount of money donation to the charity organization is permanently growing.

If we consider the above issues from the viewpoint of their future, we'll see that the global agendas of the abovementioned processes have to be developed. The most fundamental question is as follows: what will be the priorities of further global development of the near and more remote future? It's a very acute question because the virologists foresee a next wave of the pandemics. And what will be with the other diseased, chronic invalids and the other sick.

Taking the timing issue more generally, I should mention that this issue isn't technological only. If we applying the systemic and interdisciplinary approaches to a dynamics of the global whole we should realize that the tempo-rhythms of its future transformations fully depend on the values and goals of its natural and social agents.

\section{Conclusion}

The modern world evolution has nonlinear, uncertain and unpredictable character. At the same time any environment has double i.e. passive-active nature, therefore when its carrying capacity is overcoming, it usually transforms into a multisided actor.

It means that mono-disciplinary approach to modern multisided transformations has become outdated. All current global events including critical situations have systemic i.e. interdepended character. Any systemic events or processes 
should be studied by the interdisciplinary approach.

In our tightly integrated and mobile world, the systemic and interdisciplinary approaches have their limits because these approaches are only the scientific but not the political instruments.

When every participant of global market not only requires new resources but possesses such destructive arms as the nuclear, biological or climate weapons, the systemic approach may only indicate these threats but not serve as the method of reconciliation of the competing parts. Besides, the more our SBT-system is becoming complex, it simultaneously is becoming more chaotic and less dirigible.

In other words, the global market (in the widest sense of the word) has its dark side. The more its participants have the abovementioned deadly weapons the more humanity is distanced from its ideal: to be simultaneously a developmental and sustainable one. It's impossible to simultaneously develop its economic and military potential and to think that the other participants will maintain the same way of life.

Everybody can see that the current pandemics instead of uniting political and scientific forces have produced even more deep division between the so-called western democracies and the authoritarian regime in some others. Their prospects, relationships and trajectories of development are the acute issues of systemic and interdisciplinary approach. The reverse side of the same coin is a variety of possible impact of the developing global SBT-system on natural, social, political and complex environments including their feedback on the above system, humanity and his institutions, on the wellbeing of the earth population. It is another and the most difficult and acute issues of the systemic approach development. As the same time it is the key moment of the way to an actual interdisciplinary approach to the study of the structure and dynamics of global SBT-systems.

The uncertain and unpredictable development of our world is one more strategic issue of the integrated science as a social institution. It follows that the systemic prognoses of the near and remote future and then the construction of various scenarios of global development and its feedbacks are absolutely necessary in order to prevent the new CSs.

I'd to remind that in all abovementioned cases the material and social resources accumulated by any agent of the global whole are gradually exhausted in the run of time. In the final analysis it leads to reconfiguration of the leading forces on the global arenas.

\section{Conflicts of Interest}

The author declares no conflicts of interest regarding the publication of this paper.

\section{References}

(2018). Global Risk Report. Geneva: World Economic Forum.

Bauman, Z. (2017). A Chronicle of Crisis: 2011-2016 (163 p.). London: Social Europe 
Edition.

Beck, U. (1999). World Risk Society (184 p.). Malden, MA: Polity Press.

Brundtland, G., \& Khalid, M. (1987). Our Common Future. The World Commission on Environment and Development (383 p.). Oxford: Oxford University Press.

Castells, M. (2004). The Internet Galaxy. Reflections on the Internet, Business, and Society (292 p.). Oxford: Oxford University Press.

Commoner, B. (1971). The Closing Circle. New York: Knopf.

Deelstra, T., \& Yanitsky, O. (1991). Cities of Europe: The Public's Role in Shaping the Urban Environment (393 p.). Moscow: Mezhdunarudnye Otnosheniya.

Fisher-Kowalski, M. (1997). Society's Metabolism: On the Childhood and Adolescence of a Rising Conceptual Star. In M. Redklift, \& G. Woodgate (Eds.), The International Handbook of Environmental Sociology (pp. 119-137). Northampton, MA: Edward Elgar.

Meadows, D. H., Meadows, D. L., \& Randers, J. W. (1989). The Limits to Growth. A Report for the Club of Rome's Project on the Predicament of Mankind (2nd ed.). New York: Universe Books.

Meadows, D. L., \& Meadows, D. H. (1973). Toward Global Equilibrium. Cambridge, MA: Wright-Allen Press.

Park, R. (1928). Migration and the Marginal Man. American Journal of Sociology, 33, 882-893. https://doi.org/10.1086/214592

Park, R. (1952). Human Communities: The City and Human Ecology (256 p.). Glencoe, IL: Free Press.

Park, R., Burgess, R., \& McKenzie, R. (1926). The City. Chicago, IL: The University of Chicago Press.

Schwab, K. (2016). The Fourth Industrial Revolution. Geneva: World Economic Forum.

Simonov, E. (2020). Lessons of the Sardoba: To Learn But Not to Forget. Living Asia.

Stokols, D. (2018). Social Ecology in the Digital Age. Solving Complex Problems in a Globalized World (399 p.). Cambridge, MA: Academic Press.

Urry, J. (2003). Global Complexity. Cambridge: Polity Press.

Urry, J. (2008). Mobilities. Cambridge: Polity Press.

Vernadsky, V. L. (1977). The Thoughts of a Naturalist. The Scientific Thought as a Planetary Phenomenon (191 p.). Moscow: Nauka Publishers.

Von Weizsäcker, E., \& Wijkman, A. (2018). Come On! Capitalism, Short-Termism, Population, and the Destruction of the Planet. Berlin: Springer.

https://doi.org/10.1007/978-1-4939-7419-1

Yanitsky, O. (2014). Sociology of Critical Areas. Open Journal of Social Science Research, 2, 112-118.

Yanitsky, O. (2016). Sociobiotechnical Systems: A New Approach to Man-Nature Interactions. In O. Yanitsky (Ed.), On Globalization and Its Environmental Consequences (pp. 123-135). Moscow: IS RAS. http://www.isras.ru/index.php? id1198\&id=4603

Yanitsky, O. (2019). A Transition Period: Research Aims, Theory, Practice (287 p.). Moscow: Political Encyclopaedia Editorial House.

Yanitsky, O. (2019a). Some Reflections before the Beginning of the Research Project on Modern Natural and Technological Challenges in Russia. Advances in Social Sciences Research Journal, 6, 1-8. https://doi.org/10.14738/assri.611.7326 